\title{
EL DERECHO DE CONSULTA A LAS COMUNIDADES CAMPESINAS SOBRE LA EXPLOTACIÓN DE RECURSOS NATURALES EN SUS TIERRAS COMUNALES: COMENTARIOS A LA SENTENCIA DEL TRIBUNAL CONSTITUCIONAL PERUANO EN EL EXPEDIENTE N $^{\circ}$ 03343-2007-PA/TC
}

\author{
Ricardo Vinatea Medina*
}

\begin{abstract}
Resumen
La decisión contenida en el Expediente $\mathrm{N}^{\circ}$ 3343-2007-PA/TC se basa en temas formales, y no en función de temas tangenciales al caso concreto, perdiendo la oportunidad de expedir un precedente vinculante que efectivice los derechos a la identidad étnica y cultural de las comunidades nativas, el derecho a la Consulta previa, y el derecho a participar en la ejecución y evaluación de políticas que los afectan directamente.
\end{abstract}

Palabras clave: Comunidades nativas - Consulta previa - Explotación de recursos naturales.

\begin{abstract}
The decision contained in Docket $\mathrm{N}^{\circ} 3343-2007-\mathrm{PA} / \mathrm{TC}$ is based on formal issues and not on issues tangential to the specific case, which prevents a binding precedent from being rendered in order to make effective the rights of native communities to an ethnic and cultural identity, the right to previous consultation, and the right to participate in the execution and evaluation of policies directly affecting them.
\end{abstract}

Key words: Native communities - Previous consultation - Natural resources exploitation.

\section{Sumilla}

1. Introducción. 2. La demanda, la posición de las partes y la solicitud de información. 3. Análisis del caso en la sentencia del Tribunal Constitucional. 3.1. Determinación de la existencia de una superposición entre un área de exploración y el área protegida. 3.2. Legalidad y constitucionalidad de la explotación de recursos no renovables ubicados dentro del área protegida. 3.3. Cumplimiento de los requisitos previstos para la exploración y explotación. 4. Comentario. 4.1. Marco normativo nacional. 4.2. Sobre el Convenio $N^{\circ} 169$ de la Organización Internacional del Trabajo y el derecho a la Consulta. 5. Conclusiones.

\footnotetext{
* Juez Provisional de la Corte Suprema de Justicia de la República - Poder Judicial de Perú.
} 


\section{INTRODUCCIÓN}

La sentencia del Tribunal Constitucional en el Expediente $N^{\circ}$ 03343-2007-PA/ TC, expedida el 19 de febrero de 2009 constituye un precedente en el ámbito de los deberes de regulación específica del Estado peruano respecto a las normas protectoras de los derechos de las comunidades nativas y toca los temas de participación de estas en las actividades que las afecten, así como el reconocimiento de los deberes de las empresas que realizan actividades económicas en territorios de las comunidades.

El presente trabajo, teniendo como base la sentencia del Tribunal Constitucional mencionada, abordará críticamente determinados aspectos jurídicos conceptuales y normativos en relación con la regulación de la participación de los ciudadanos de las comunidades nativas en materia ambiental. En esa medida, la importancia de la sentencia bajo comentario estriba en que hace referencia a los importantes desarrollos en el derecho internacional del derecho de consulta a los pueblos indígenas sobre la explotación de recursos naturales en sus tierras comunales, como se precisa en el Convenio $N^{\circ} 169$ de la Organización Internacional del Trabajo.

Para los fines propuestos, la investigación queda dividida en tres apartados, en el primero describimos el proceso de amparo que llevó al pronunciamiento del Tribunal Constitucional, la posición de las partes en el conflicto y la solicitud de información efectuada por este último para una mejor toma de la decisión, el segundo apartado describe el razonamiento del máximo intérprete de la Constitución para ordenar la paralización de las actividades de exploración y explotación de recursos naturales en el área protegida que comprende el territorio comunal de sesenta y cuatro comunidades nativas de grupos étnicos pertenecientes a las familias Cocama Cocamilla y Chayahuita, por incumplimiento de normas administrativas de preservación de zonas protegidas; para, en el tercer apartado realizar un comentario crítico respecto a la falta de precisión del imprescindible requisito de consulta previa a cualquier actividad de explotación de recursos naturales en las tierras ancestrales de los pueblos indígenas, advirtiendo que si bien la sentencia bajo comentario desarrolla un acápite sobre el tema, en sus próximas sentencias el Tribunal Constitucional debería precisar los contornos legales para la implementación efectiva de esta obligación del Estado peruano, para que la judicatura nacional pueda proteger de mejor manera los derechos de los pueblos originarios. 


\section{LA DEMANDA, LA POSICIÓN DE LAS PARTES Y LA SOLICITUD DE INFORMACIÓN}

El ciudadano Jaime Hans Bustamante Johnson interpone demanda de Amparo el 13 de octubre de 2006 contra las empresas Occidental Petrolera del Perú; LLC, Sucursal del Perú (hoy Talismán Petrolera del Perú, LLC Sucursal del Perú), Repsol Exploración Perú, Sucursal del Perú (en adelante REPSOL) y Petrobras Energía Perú S.A. (en adelante PETROBRAS), alegando como derechos vulnerados:

- Derecho a gozar de un ambiente equilibrado y adecuado al desarrollo de su vida;

- Derecho a la vida, el libre desarrollo y el bienestar;

- Protección de la salud, la del medio familiar y la de la comunidad, así como el deber de contribuir a su promoción y defensa;

- A exigir del Estado la promoción de la conservación de la diversidad biológica y las áreas naturales protegidas;

- Derecho a la alimentación; y,

- Derecho al agua.

El petitorio consta de dos solicitudes:

- Reponer las cosas al momento en que se inició la amenaza de violación de dichos derechos $\mathrm{y}$,

- La suspensión de la exploración y la eventual explotación de hidrocarburos en el área natural protegida "Cordillera Escalera".

El Juzgado Especializado en lo Civil de San Martín (31 de enero de 2007) declaró infundada la demanda: El impacto en la zona de los trabajos de exploración ha sido mínimo (en base a las conclusiones del informe técnico presentado por el perito de ingeniería ambiental). Solo se ha usado agua para consumo humano directo del personal. El agua necesita tratamiento previo para el consumo humano pero no hay niveles de contaminación relevantes o que representen un peligro para la población de zonas aledañas (en base al análisis de la muestra de la Quebrada del río Charapillo).

La Primera Sala Mixta Descentralizada de la Corte Superior de Justicia de San Martín (10 de mayo de 2007) confirma la apelada: no existe amenaza de violación al medio ambiente (en base al informe de evaluación del estudio de impacto ambiental del proyecto de exploración sísmica de la estructura Pihuicho en el lote 103). No se ha generado impactos ambientales de envergadura, 
no se hizo uso del recurso hídrico, y no existe afectación directa o indirecta sobre el agua superficial y subterránea que atente contra el uso y consumo humano.

Según el demandante, en el lote 103 (área a explorar y explotar de las empresas demandadas) se encuentra el Área de Conservación Regional Cordillera Escalera, establecida mediante Decreto Supremo Nº45-2005-AG. Dicha área tiene especial importancia por su biodiversidad y como fuente captadora y posibilitadora de agua, ya que ahí nacen las tres cuencas hidrográficas (Cumbaza, Caynarachi y Shanusi) que son la única fuente proveedora de agua con la que cuenta la población de zonas aledañas. La explotación petrolera implica que millones de litros de agua de producción petrolera con alta salinidad serán extraídos del subsuelo y aflorarán a la superficie contaminando y devastando el medio ambiente (principalmente el agua), pues dichas aguas saladas suelen ser vertidas a los cauces de los ríos. La exploración se está realizando incumpliendo lo previsto en el artículo $27^{\circ}$ de la Ley $\mathrm{N}^{\circ} 26834$, Ley de Áreas Naturales Protegidas, que establece que el aprovechamiento de los recursos naturales en áreas naturales protegidas solo podrá ser autorizado si resulta compatible con la categoría, la zonificación asignada y el plan maestro.

Según el Procurador para los asuntos judiciales del Ministerio de Energía y Minas (MEM), este no ha violado precepto constitucional alguno, por cuanto mediante la Resolución Directoral No 360-2006-MEM/AAE, del 4 de julio de 2006, la Dirección General de Asuntos Ambientales Energéticos del MEN aprobó el Estudio de Impacto Ambiental del Proyecto de Exploración Sísmica de la Estructura Pihuicho en el lote 103, presentado por OXY.

Mientras que para la demandada Occidental Petrolera del Perú; LLC, Sucursal del Perú (OXY) y Repsol Exploración Perú, Sucursal del Perú (REPSOL), la ejecución del programa de exploración sísmica de la estructura Pihuicho en el lote 103 finalizó el 28 de octubre de 2006, por tanto, se debe aplicar el artículo 5.5 del Código Procesal Constitucional para declarar improcedente la demanda. La calificación de un territorio como "área natural protegida" no implica que no pueda ser materia de actividades humanas; no se ha realizado actividades de "aprovechamiento" de recursos naturales; y, que para la realización del programa de exploración sísmica se cumplieron los requisitos ante autoridades competentes.

Por su parte, Petrobras Energía Perú (PETROBRAS) sostiene que se debe aplicar el artículo $9^{\circ}$ del Código Procesal Constitucional y declarar improcedente la demanda porque es necesario actuar medios probatorios que permitan 
demostrar si existe una amenaza de daño al ambiente, así como la relación de causalidad entre las actividades de exploración y la supuesta amenaza. El establecimiento de un área natural protegida no es incompatible con la realización de actividades económicas. No son aplicables los principios de prevención y precautorio (parte del derecho ambiental) para imponer sanciones a los particulares, sino que son orientadores de las autoridades y estos principios ya fueron usados para autorizar el estudio de impacto ambiental del lote 103. Asimismo, los criterios de aplicación del principio precautorio no han sido acreditados por el demandante.

Para resolver el caso el Tribunal Constitucional solicitó información al INRENA, INDEPA, a la Dirección General de Asuntos Ambientales Energéticos del Ministerio de Energía y Minas, a PERUPETRO S.A., y a la Defensoría del Pueblo.

Materias constitucionales relevantes al caso:

a. Derecho a un ambiente equilibrado y adecuado. Dicho derecho fundamental está configurado por: 1) el derecho a gozar de un ambiente equilibrado y adecuado, por el que la intervención del ser humano no debe suponer una alteración sustantiva de la interrelación entre los elementos de medio ambiente, y se debe tutelar el ambiente adecuado para el desarrollo de la persona y de su dignidad; y 2) el derecho a la preservación de un ambiente sano y equilibrado, por el que existen obligaciones ineludibles para los poderes públicos de mantener los bienes ambientales en las condiciones adecuadas para su disfrute, así como para los particulares cuya actividad económica incide en el ambiente.

Respecto al derecho al ambiente equilibrado y adecuado existen derechos reaccionales - libertad negativa (obligación de los particulares y del Estado de abstenerse de realizar cualquier tipo de actos que afecten al ambiente equilibrado y adecuado para el desarrollo de la vida humana) - como derechos prestacionales - libertad positiva (a los particulares y el Estado de evitar, proteger y/o reparar los daños inevitables que se produzcan). Es importante la prevención ya que siempre es preferible evitar el daño (principio de prevención y principio de precaución) a tener que indemnizar perjuicios (principio contaminador-pagador) que pueden ser sumamente costosos para la sociedad.

b. Medio ambiente y Constitución ecológica. Los derechos fundamentales vinculan tanto al Estado como a los particulares. El conjunto de disposicio- 
nes de la carta fundamental, referidas a las relaciones entre el individuo, la sociedad y el medio ambiente se denomina "Constitución Ecológica". Al ser los recursos naturales, in totum, patrimonio de la nación, su explotación no puede ser separada del interés nacional, y los beneficios derivados de su utilización deben alcanzar a la nación en su conjunto; por ende, se proscribe su exclusivo y particular goce. Los servicios ambientales que prestan ciertas áreas del territorio de la nación benefician no solo al país, sino también a la región e inclusive a todo el planeta, por ello el Estado debe asumir la protección de estas riquezas, lo que se manifiesta por medio de la implantación de áreas especialmente protegidas, evitando la afectación de los servicios ambientales como la captación y almacenamiento de agua.

c. Desarrollo sostenible y generaciones futuras. El uso sostenible es la utilización de componentes de la diversidad biológica de un modo y a un ritmo que no ocasione la disminución a largo plazo de dicha diversidad; cuando se explotan recursos no renovables, como los posibilitadores, debe cuidarse en no comprometer aquella diversidad biológica. El principio de sostenibilidad pretende modular la actividad económica a la preservación del ambiente. Una interpretación sistemática de las normas de la Constitución económica indica que el reconocimiento de que los recursos naturales (especialmente los no renovables) es una manifestación concreta del derecho a disfrutar de un entorno ambiental idóneo para el desarrollo de la existencia; que estos recursos sean objeto de un aprovechamiento razonable y sostenible; y que los beneficios resultantes de tal aprovechamiento deben ser a favor de la colectividad en general (promoviendo el Estado las políticas a tal efecto).

d. Medio ambiente y principio de prevención. El principio de prevención y el principio precautorio están íntimamente relacionados, pero existe una distinción ya que en la prevención el riesgo de daño ambiental se conoce anticipadamente y se puede adoptar medidas para neutralizarlo (se conoce la peligrosidad de la actividad pero se ignora la producción de un daño en un caso concreto). Por el contrario, en la precaución, el riesgo de daño ambiental no puede ser conocido anticipadamente (ante la imposibilidad de conocer los efectos a medio y largo plazo de una acción), por tanto, la posibilidad de anticipación es limitada e imperfecta.

e. Medio ambiente y responsabilidad social de la empresa. En un Estado social y democrático de derecho, de economía social de mercado y de desarrollo sostenible, la responsabilidad social constituye una conducta exigible ineluctablemente a la empresa. La finalidad de lucro debe ir con 
una estrategia previsora del impacto ambiental que la labor empresarial genera. La Constitución ordena que la actividad extractiva de recursos naturales se realice en equilibrio con el entorno y con el resto del espacio que configura el soporte de vida y de riqueza natural y cultural. Si la actividad empresarial genera pasivos ambientales se generará lucro pero a un costo que el Estado y la sociedad no soportarán.

f. Comunidades nativas y medio ambiente. En el lote 103 existen 64 comunidades nativas de grupos étnicos pertenecientes a las familias Cocama Cocamilla y Chayahuita, por tanto, el Tribunal considera apropiado analizar tangencialmente la temática relativa a los pueblos indígenas.

i. Derecho a la identidad étnica y cultural. Es obligación del Estado proteger la pluralidad étnica y cultural existente en la nación. La propia Constitución reconoce la autonomía organizativa, económica y administrativa a las comunidades nativas, así como la libre disposición de sus tierras (incluidas las funciones jurisdiccionales que no afecten los derechos fundamentales). El "derecho a la identidad étnica" es la facultad que tiene la persona que pertenece a un grupo étnico determinado de ser respetada en las costumbres y tradiciones propias de la etnia a la cual pertenece, evitándose con ello que desaparezca la singularidad de tal grupo. Manifestación de este derecho es "el derecho a ser escuchados y consultados en forma previa a toda acción o medida que se adopte y que pueda afectarles", así como "el derecho a participar en la formulación, diseño, ejecución, monitoreo y evaluación de los planes, programas y proyectos de desarrollo nacional, regional o local que pueda afectarles", como bien lo señala la Resolución Ministerial N 159-2000-PROMUDEH.

ii. Convenio 169 de la Organización Internacional del Trabajo y recursos naturales. Se hace referencia a jurisprudencia del Tribunal Constitucional que reconoce a los tratados internacionales de derechos humanos como parte de nuestro ordenamiento y como normas que ostentan rango constitucional (STC $\mathrm{N}^{\circ}$ 0047-2004-AI/TC, fundamento 22 y STC N ${ }^{\circ} 0025-2005-\mathrm{PI} / \mathrm{TC}$, fundamento 33). El Perú, desde diciembre de 1993, es parte del Convenio № 169 de la Organización Internacional del Trabajo, Sobre los Pueblos Indígenas y Tribales en países independientes, que reconoce el derecho a la consulta previa y a participar en la ejecución y evaluación de políticas que los afectan directamente; por tanto, su contenido es parte del derecho nacional, siendo además obligatoria su aplicación por todas las entidades estatales. 
Las situaciones jurídicas de ventaja y de desventaja son reconocidas a los grupos étnicos, según la realidad y sus concepciones sobre el mundo que los rodea. Una manifestación singular es la relación entre los pueblos indígenas y la tierra, así el término "tierras", para el caso de los pueblos indígenas, incluye el concepto de "territorio" ya que la unidad de la comunidad a su territorio excede la noción de propiedad patrimonial, un dominio espiritual y cultural de la tierra (artículo $13^{\circ}$ del Convenio $N^{\circ} 169$ ). En este sentido, la Corte Interamericana ha señalado que " [...] la estrecha relación que los indígenas mantienen con la tierra debe de ser reconocida y comprendida como la base fundamental de sus culturas, su vida espiritual, su integridad y su supervivencia económica", caso de la Comunidad Mayagna - Sumo - Awas Tigni vs. Nicaragua.

La libre autodeterminación es la capacidad de los pueblos indígenas de organizarse de manera autónoma, sin intervenciones de índole política o económica por parte de terceros, y la facultad de aplicar su derecho consuetudinario a fin de resolver los conflictos sociales surgidos al interior de la comunidad, siempre que en el ejercicio de tal función no se vulneren derechos fundamentales de terceros, de los cuales el Estado es garante. Este concepto es la base del de consulta previa, esto es que "cada vez que se prevean medidas legislativas o administrativas susceptibles de afectar directamente a los pueblos indígenas, el Gobierno tendrá que consultar previamente y mediante los procedimientos apropiados e instituciones representativas [...] deberán efectuarse de buena fe y de forma apropiada a las circunstancias del caso, con la finalidad de llegar a un acuerdo y lograr el consentimiento de las medidas propuestas" (artículo $6^{\circ}$, literal a) del Convenio $N^{\circ} 169$ de la Organización Internacional del Trabajo), ya que los pueblos indígenas tienen derecho a decidir sobre sus propias prioridades, debiendo participar en la formulación, "aplicación y evaluación de los planes y programas de desarrollo nacional y regional susceptibles de afectarles directamente" (artículo $7^{\circ}$ del Convenio Nº 169 de la Organización Internacional del Trabajo). Más directamente, los gobiernos deberán establecer procedimientos mediante los cuales se pueda consultar a los pueblos interesados "antes de emprender o autorizar cualquier programa de prospección o explotación de los recursos existente en sus tierras." (artículo $15^{\circ}$ del Convenio $N^{\circ} 169$ de la Organización Internacional del Trabajo). Esto se refiere a brindar con la debida anticipación la información relativa al tipo de recurso a explotar, las áreas de explotación, informes sobre impacto ambiental, además de las posibles empresas que podrían efectuar la explotación del recurso. Con la finalidad de que al interior del grupo étnico se inicien las reflexiones y diálogos sobre el plan a desarrollar. Luego viene la etapa de participación con el debate entre las partes, para llegar finalmente a la Consulta (sin ninguna coerción). La propia Corte Interamericana ha reconocido incluso el derecho 
de los integrantes de los pueblos indígenas y tribales de ser titulares de los recursos naturales que tradicionalmente habían usado en su territorio, aunque no absoluto, así señala la Corte que “[...] el Estado tiene la obligación, no solo de consultar a los Saramakas, sino también debe obtener el consentimiento libre, informado y previo de estos, según sus costumbres y tradiciones [...]", caso del Pueblo de Saramaka vs. Surinam)

En la normativa nacional también se reconoce el derecho a la Consulta (Decreto Supremo $N^{\circ}$ 012-2008-EM), que es también un reflejo de la responsabilidad social de la empresa. En este sentido, respecto al presente caso, la empresa, así como entidades del Estado han llevado a cabo una serie de talleres donde se transmitió a las comunidades nativas información sobre la empresa y los distintos procesos que se van a desarrollar en las zonas aledañas. Sin embargo, es real que no existe una norma general que desarrolle los alcances, detalles, condiciones y vinculatoriedad del derecho de consulta establecido en el Convenio $\mathrm{N}^{\circ} 169$ de la Organización Internacional del Trabajo, tarea que queda a cargo del legislador.

\section{ANÁLISIS DEL CASO EN LA SENTENCIA DEL TRIBUNAL CONSTITUCIONAL}

\subsection{Determinación de la existencia de una superposición entre un área de exploración y el área protegida}

De acuerdo a los mapas remitidos por el Instituto Nacional de Recursos Naturales (en adelante INRENA) se aprecia claramente que gran parte de las 149.870,00 hectáreas del Área de Conservación Regional "Cordillera Escalera" (se encuentra en los distritos de Pinto Recodo, San Roque de Cumbaza, Pongo del Caynarachi y Barranquita de la provincia de Lamas y de los distritos de San Antonio de Cumbaza, Tarapoto, La Banda de Shilcayo, Shapaja y Chazuta de la provincia de San Martín, de la región San Martín) se encuentra dentro del lote 103 (área concesionada ubicada entre las provincias de Alto Amazonas del departamento de Loreto y Moyabamba, Lamas, San Martín y Picota del departamento de San Martín).

\subsection{Legalidad y constitucionalidad de la explotación de recursos no renova- bles ubicados dentro del área protegida}

Entre las finalidades de las áreas protegidas encontramos: asegurar la continuidad de los procesos ecológicos y evolutivos, mantener la biodiversidad y mantener la base de recursos, incluyendo los genéticos, que permitan de- 
sarrollar opciones para mejorar los sistemas productivos, encontrar adaptaciones frente a eventuales cambios climáticos perniciosos (artículo $2^{\circ}$ de la Ley No 26834 de Áreas Protegidas). Las Áreas de Conservación Regional (en adelante ACR) se clasifican como áreas de uso directo, pudiendo, en consecuencia, explotarse los recursos naturales ubicados en la zona (en virtud del artículo $20^{\circ}$ de la Ley $N^{\circ} 26834$ sí está permitido el aprovechamiento o extracción de recursos en este tipo de áreas, siempre que ello sea compatible con los objetivos del área). En las Áreas Naturales Protegidas (en adelante ANP) de uso directo pueden realizarse actividades extractivas, inclusive cuando se trata de recursos no renovables; pero solo podrá ser autorizado si resulta compatible con la categoría, zonificación asignada y el plan maestro del área. El aprovechamiento de recursos no debe perjudicar el cumplimiento de los fines para los cuales se ha establecido el área (artículo $27^{\circ}$ de la Ley $\mathrm{N}^{\circ} 26834$ y en el mismo sentido el artículo $5^{\circ}$ del Decreto Supremo $N^{\circ}$ 045-2005-AG, que crea las ACR).

El Tribunal Constitucional señala también que a pesar que la concesión para la exploración y explotación posibilitadoras (20 de julio de 2004) fue anterior a la existencia de la ACR “Cordillera Escalera” (25 de noviembre de 2005), debe preferirse un criterio más amplio y comprensivo de los elementos que significan la creación de una ANP y la profunda incidencia que una afectación grave en su entorno puede provocar en la sociedad (fundamentos jurídicos 48 y 49).

Además, el Tribunal Constitucional indica que si bien es cierto que la etapa exploratoria ya ha sido llevada a cabo, esto no puede significar que la amenaza ya ha cesado, en tanto dicha exploración sísmica constituye solo una fase de la etapa de exploración, quedando pendiente otras, como la perforación de pozos exploratorios que se extiende incluso hasta cuarenta años (las fases y plazos están comprendidos en el Contrato de Licencia entre Perúpetro S.A. y Occidental Petrolera del Perú). Resaltando que la etapa de exploración comprende, además de la exploración sísmica, otro tipo de actividades. Asimismo, señala que la obligación del Estado implica que los actos que puedan representar un nivel de riesgo para las áreas naturales protegidas requieren, para efectos de su aprobación, una participación conjunta de los distintos organismos estatales (fundamentos jurídicos 50 al 53).

\subsection{Cumplimiento de los requisitos previstos para la exploración y explotación}

El estudio de impacto ambiental del proyecto de exploración sísmica de la estructura Pihuicho en el Lote 103, fue aprobado (4 julio de 2006) previamente 
al inicio de las actividades por la Dirección General de Asuntos Ambientales Energéticos (DGAAE) del Ministerio de Energía y Minas, como lo señala el artículo $9^{\circ}$ y $26^{\circ}$ del Reglamento para la Protección Ambiental en las Actividades de Hidrocarburos - Decreto Supremo N015-2006-EM.

Ya que la exploración sísmica constituye solo una fase de la etapa de exploración, el Tribunal Constitucioal analizará si las actividades restantes y la posibilidad de explotación pueden ser consideradas una amenaza al derecho constitucional a gozar de un ambiente equilibrado y adecuado al desarrollo de la vida. Del Informe de INRENA (Informe $N^{\circ} 177-2008-I N R E-$ NA-IANP-DPANP) y del Decreto Supremo N 045-2005-AG, que indican principalmente que la ACR constituye una "porción de la selva alta donde nacen importantes ríos que abastecen de agua a la población humana de las ciudades más importantes de la Región San Martín y alberga una singular diversidad biológica cuya conservación, a través de su protección y uso sostenible, constituye una prioridad regional y nacional"; así también, que es una "zona prioritaria para la conservación de mamíferos, anfibios, reptiles y aves, ya que alberga especies de distribución muy restringida"; el Tribunal Constitucional concluye que la ACR "Cordillera Escalera" es un área relevante no solo para el país en conjunto, sino en especial para la región San Martín; y reconoce como sus objetivos generales el conservar y proteger los recursos naturales y la diversidad biológica de los ecosistemas frágiles que se encuentran en la Cordillera Escalera; así como asegurar la continuidad de los procesos biológicos en los ecosistemas del área propuesta (fundamento jurídico 59).

Señala el Tribunal que se impone la necesidad de implementar fórmulas para que se realicen las actividades de exploración y explotación de hidrocarburos, pero conciliándolas con la conservación de los recursos y elementos ambientales. Es función del Estado (en consonancia con el artículo $67^{\circ}$ de la Constitución) auspiciar el equilibrio dinámico entre el desarrollo socioeconómico de la nación y la protección y conservación de un disfrute permanente; pretiriendo formas de exploración y explotación de hidrocarburos irrazonables, que en sí mismas puedan ser destructivas y no sostenibles para el desarrollo regional y el beneficio de las generaciones. Por tanto para efectos de este caso, el Tribunal Constitucional considera que es "necesario conciliar el impacto ambiental que generarían las diversas actividades que comprenden las etapas de exploración y explotación de hidrocarburos en el lote 103 con la protección de la biodiversidad y el derecho a gozar de un ambiente equilibrado y adecuado al desarrollo de la vida". 
Para efectos de lo anterior se aplican los principios de desarrollo sostenible y de prevención (este último cuenta con pleno reconocimiento en la normativa así como en la jurisprudencia) y se debe tener en cuenta que los instrumentos de gestión ambiental desempeñan un rol de suma relevancia en relación con la prevención; es indispensable tenerlos en cuenta al referirse al desarrollo sostenible de la explotación posibilitadora que respete la biodiversidad y las áreas naturales protegidas. En virtud de la normatividad revisada el Tribunal señala que el Estado debe promover el aprovechamiento sostenible de los recursos naturales por leyes especiales, políticas del desarrollo sostenible, generación de infraestructura y fomento del conocimiento científico, libre iniciativa e innovación productiva (artículo $7^{\circ}$ de la Ley $N^{\circ} 26821$ - Ley Orgánica para el Aprovechamiento Sostenible de los Recursos Naturales); pero tal aprovechamiento solo procederá si es que la explotación a realizar es compatible con el Plan Maestro del área protegida; y solo sería permitido el aprovechamiento de recursos no renovables si el Plan Maestro así lo permite (artículo $27^{\circ}$ de la Ley de Áreas Naturales Protegidas y artículo $5^{\circ}$ del Decreto Supremo $\left.\mathrm{N}^{\circ} 045-2005-\mathrm{AG}\right)$.

El Tribunal rechaza la interpretación de los demandados en el sentido que el plan maestro es un mandato de preceptividad aplazada que requiere la actuación especial del Estado a través de instituciones especializadas y que por la inexistencia del Plan no pueden impedirse las actividades de exploración menos cuando la empresa no ha realizado actividades de explotación de recursos que puedan calificarse como "aprovechamiento" de recursos naturales. Señala el Tribunal que si bien es cierto la inexistencia del referido plan maestro ha sido responsabilidad de las autoridades estatales competentes y no de las empresas emplazadas. En aplicación del principio de prevención respecto a una ANP se considera que la etapa de exploración y explotación constituyen un todo que conduce al aprovechamiento de los recursos naturales; sin dejar de tener en cuenta para lograr un equilibrio (entre la debida protección del medio ambiente y el aprovechamiento razonable de los recursos naturales, de un lado, y la libertad empresarial constitucionalmente ejercida, de otro), que no toda la etapa de exploración tiene el mismo grado de incidencia en el medio ambiente. Ya que son solo las últimas las que puede considerarse que comprometen nítidamente el contenido constitucionalmente protegido del derecho fundamental al medio ambiente, el Tribunal Constitucional considera imprescindible que se cuente con un plan maestro elaborado por las autoridades competentes, a fin de que pueda llevarse a cabo tanto la última fase de la etapa de exploración como la respectiva y posterior etapa de explotación (fundamentos jurídicos 65 al 67). 
En conclusión:

- Queda prohibida la realización de estas actividades mientras no se cuente con el respectivo plan maestro.

- Si las actividades ya se encuentran en curso, deben quedar suspendidas mientras no se cuente con el referido plan maestro.

- El plan maestro debe contemplar la posibilidad de aprovechar los recursos naturales que se encuentran en el Área de Conservación Regional "Cordillera Escalera", sujetándose a las normas de protección ambiental y a las limitaciones y restricciones previstas en los objetivos de creación del área y su zonificación.

Finalmente, exhorta a las empresas en el sentido que lo decidido no perjudique la materialización de su responsabilidad social con la población asentada en el lote 103, ya que en virtud del enfoque preventivo, es esencial e inherente al concepto de la responsabilidad social de la empresa los aspectos retributivos a las comunidades afincadas en el área de influencia de las actividades de exploración y explotación.

El Tribunal Constitucional declara fundada la demanda. Prohíbe la realización de la última fase de la etapa de exploración y la etapa de explotación dentro del Área de Conservación Regional denominada "Cordillera Escalera" hasta que no se cuente con el plan maestro, pudiendo reiniciar tal actividad una vez que este haya sido elaborado y se establezca la compatibilidad entre la actividad de exploración y explotación y los objetivos del Área de Conservación Regional "Cordillera Escalera". Si ya se encuentra en ejecución la última fase de la etapa de exploración o la etapa de explotación, dichas actividades deben quedar inmediatamente suspendidas.

\section{COMENTARIO}

En la sentencia del Tribunal Constitucional bajo comentario, estamos frente a un caso en el que están involucradas áreas naturales protegidas en las cuales coexisten sesenta y cuatro comunidades nativas de grupos étnicos pertenecientes a las familias Cocama Cocamilla y Chayahuita que se vieron afectadas por actividades exploratorias (actividades de exploración sísmica) realizadas en el marco de un contrato de explotación posibilitadora entre el Estado y empresas que se dedican a este ramo. En este contexto el Tribunal Constitucional nacional ve conveniente desarrollar las materias relevantes conexas como el derecho a un ambiente equilibrado y sano, la regulación constitucional del medio ambiente, el medio ambiente y su afectación a las generaciones futuras, así como los 
principios que regulan la conservación del medio ambiente: preventivo y precautorio, después, la relación entre medio ambiente y responsabilidad social de la empresa; para finalmente desarrollar los temas relacionados con las comunidades nativas y el medio ambiente, esto es, los derechos a la identidad étnica y cultural, así como la relevancia del Convenio de la Organización Internacional de Trabajo que reconoce el derecho a la consulta previa.

\subsection{Marco normativo nacional}

En el presente caso el Tribunal Constitucional señala que la empresa, así como entidades del Estado han llevado a cabo una serie de talleres donde se transmitió a las comunidades nativas información sobre la empresa y los distintos procesos que se van a desarrollar en las zonas aledañas. Esto se realizó en virtud de una regulación insuficiente que no satisface las obligaciones estatales y de los particulares establecidas en el Convenio № 169 de la Organización Internacional de Trabajo. A continuación repasaremos la regulación nacional vigente.

El Perú, desde diciembre de 1993 con la Resolución Legislativa N²6253, es parte del Convenio $N^{\circ} 169$ de la Organización Internacional del Trabajo sobre los Pueblos Indígenas y Tribales en países independientes, que reconoce el derecho a la consulta previa y a participar en la ejecución y evaluación de políticas que los afectan directamente; por tanto, su contenido es parte del derecho nacional, siendo además obligatoria su aplicación por todas las entidades estatales.

La Constitución política con el contenido de las normas denominadas "Constitución ecológica" otorga el marco para la explotación de los recursos naturales y establece claramente la obligación del Estado en asumir la protección de las riquezas naturales por medio de la implantación de áreas especialmente protegidas, evitando la afectación de los servicios ambientales como la captación y almacenamiento de agua.

La Resolución Ministerial N 535-2004-MEM-DM, disponía la realización de talleres y consultas a las comunidades que podían verse afectadas. Así se buscaba materializar el contenido del Convenio $\mathrm{N}^{\circ} 169$. Esta norma se vio modificada en materia específica por el Decreto Supremo Nº12-2008-EM, del 19 de febrero de 2008, que tiene por objeto fortalecer los derechos de acceso a la información, a la participación ciudadana en la gestión ambiental y social, así como los derechos de los pueblos indígenas y la población involucrada. En dicha normativa se establece que la "consulta es una forma de 
participación ciudadana" de aquellas poblaciones que podrían verse afectadas por un proyecto de hidrocarburos.

Posteriormente se dio el Decreto Supremo Nº02-2009-MINAM, Reglamento sobre Transparencia, Acceso a la Información Pública Ambiental y Participación y Consulta Ciudadana en Asuntos Ambientales, que tiene entre sus finalidades regular los mecanismos y procesos de participación y consulta ciudadana en los temas de contenido ambiental.

La Ley del Ministerio del Ambiente, Decreto Legislativo No 1013, señala entre sus objetivos y funciones específicas el promover la participación ciudadana en los procesos de toma de decisiones para el desarrollo sostenible (artículo $3.2 \mathrm{c} \mathrm{y} \mathrm{artículo} 7^{\circ}$, a). Finalmente, la Ley General del Ambiente, Ley $\mathrm{N}^{\circ} 28611$ (15 de octubre de 2005) señala en su Título Preliminar (artículo III) que "Toda persona tiene el derecho a participar responsablemente en los procesos de toma de decisiones, así como en la definición y aplicación de las políticas y medidas relativas al ambiente y sus componentes, que se adopten en cada uno de los niveles de gobierno. El Estado concerta con la sociedad civil las decisiones y acciones de la gestión ambiental." Así también dedica un capítulo completo (Capítulo 4 del Título I) al acceso a la información ambiental y participación ciudadana, en el que se incorporan aspectos como la obligación del Estado de diseñar el marco tributario nacional, considera los objetivos de la política nacional ambiental; lineamientos ambientales básicos en la elaboración de las políticas públicas; definición de objetivos en la planificación y ordenamiento territorial; en la elaboración de estándares de calidad ambiental y límites máximos permisibles se tomen en cuenta los parámetros establecidos por la Organización Mundial de la Salud.

\subsection{Sobre el Convenio $\mathbf{N}^{\circ} 169$ de la Organización Internacional de Trabajo y el derecho a la consulta}

Los conflictos entre el régimen de los derechos humanos, y en particular entre el conjunto de derechos indígenas con los privilegios de los inversionistas, pueden darse en un número de áreas. En el ámbito de las normas, pueden surgir conflictos entre el derecho a establecer la inversión con el derecho a la consulta previa, así como entre el derecho a la propiedad intelectual con el derecho a la distribución equitativa de los beneficios derivados de tales derechos. También pueden existir conflictos entre los mecanismos de solución de controversias, por ejemplo entre un tribunal arbitral y la Comisión Interamericana de Derechos Humanos ${ }^{1}$. 
La consulta se fundamenta en el derecho que tienen los pueblos de decidir sus propias prioridades en lo que atañe al proceso de desarrollo, en la medida en que este afecte sus vidas, creencias, instituciones y bienestar espiritual y a las tierras que ocupan o utilizan de alguna manera, y de controlar, en lo posible, su propio desarrollo económico, social y cultural; además, en el derecho de dichos pueblos a participar en la formulación, aplicación y evaluación de los planes y programas de desarrollo nacional y regional susceptibles de afectarles directamente (artículo $7^{\circ}$ del Convenio $N^{\circ} 169$ de la Organización Internacional de Trabajo).

Este mecanismo de participación es un derecho constitucional colectivo y un proceso de carácter público especial y obligatorio que debe realizarse previamente, siempre que se vaya a adoptar, decidir o ejecutar alguna medida administrativa y legislativa o proyecto público o privado susceptible de afectar directamente las formas de vida de los pueblos indígenas en su aspecto territorial, ambiental, cultural, espiritual, social, económico y de salud y otros que incidan en su integridad étnica ${ }^{2}$.

La consulta es un derecho fundamental que busca asegurar el respeto y protección de la integridad, capacidad y decisión de los pueblos y comunidades antes que se adopten decisiones o se prevean medidas legislativas, administrativas, planes y programas de desarrollo que los involucren. Cualquier proceso de consulta debe comprender la información plena, el consentimiento y la oposición a la medida consultada. Es decir, la consulta es previa porque debe realizarse asegurando la libre participación de los consultados. Además, la consulta es permanente porque adoptada la decisión en alguna materia, se debe garantizar la participación indígena en la implementación. Debe entenderse que el consentimiento y la oposición a alguna medida propuesta constituye la finalidad fundamental de la consulta, por lo cual esa decisión deberá ser libre y con pleno conocimiento de sus implicancias ${ }^{3}$.

La Corte Constitucional de Colombia, en su Sentencia SU-039, del 3 de febrero 1997, en el caso del pueblo indígena U'wa, sostuvo contundentemente que no puede hablarse de protección de la diversidad étnica y cultural y de su reconocimiento, si no se otorga, en el plano constitucional, personería sustantiva a las diferentes comunidades indígenas, que es lo único que les confiere status para gozar de los derechos fundamentales y exigir, por sí mismas, su protección cada vez que ellos les sean conculcados. Añadió que la explotación de los recursos naturales en los territorios indígenas hace necesario armonizar dos intereses contrapuestos: la necesidad de planificar el manejo y el aprovechamiento de los recursos naturales en los referidos territorios para garantizar 
su desarrollo sostenible, su conservación, restauración o sustitución (artículo constitucional $80^{\circ}$ ), y la de asegurar la protección de la integridad étnica, cultural, social y económica de las comunidades indígenas que los ocupan ${ }^{4}$. Asimismo, deja en claro que la consulta previa se constituye en un derecho fundamental: " [...] el derecho fundamental de la comunidad a preservar la integridad se garantiza y efectiviza a través del ejercicio de otro derecho que también tiene el carácter de fundamental, como es el derecho de participación de la comunidad en la adopción de las referidas decisiones [...] pues se erige en un instrumento que es básico para preservar la integridad étnica, social, económica y cultural de las comunidades indígenas y para asegurar, por ende, su subsistencia como grupo social" 5 .

El derecho a la consulta de los pueblos indígenas es vinculante y así debe estar especificado en la legislación que apruebe el Congreso nacional, de lo contrario iría contra el espíritu del Convenio Nº 169 de la Organización Internacional de Trabajo. Si el Tribunal Constitucional reconoce como vinculante el Convenio, es obvio que es igual con los principios que se desarrollan en él. La Corte Interamericana de Derechos Humanos ha resuelto estos contenidos en sendas decisiones en los casos del Pueblo de Saramaka vs. Surinam y de la Comunidad Mayagna (Sumo) Awas Tigni vs. Nicaragua.

La sola realización de la consulta no garantiza nada más allá del propio derecho que tienen las comunidades a ser consultadas. La consulta es solo un procedimiento, un medio para lograr un fin. De que se realice o no se realice, o que se haga bien o mal, no depende la integridad de los pueblos. Se puede usar para garantizar la integridad y derechos pero también se la puede usar para legitimar su vulneración ${ }^{6}$. En consecuencia, la consulta será válida siempre que se realice mediante los procedimientos que los pueblos y comunidades consideran apropiados. Este procedimiento supone entonces, que la consulta se realice a través de las organizaciones representativas, se respete la integridad de sus valores y prácticas sociales. Es una obligación del Estado el proveer los medios materiales necesarios para la participación de los pueblos y comunidades en la consulta ${ }^{7}$.

Sistemáticamente podemos establecer que la consulta previa debe desarrollarse con los siguientes supuestos, que de ninguna manera se presentaron en el caso analizado por el Tribunal Constitucional. La buena fe, tanto de los funcionarios públicos como de los demás intervinientes e interesados en el proceso debe garantizarse, esto implica que las consultas no deben ser manipuladas, y que estas no deben darse con posterioridad a que se hayan tomado las decisiones o medidas, porque se buscaría legitimar decisiones tomadas 
por el Estado, que pueden ser inconvenientes para las comunidades. Esto no fue posible en el caso bajo comentario dado que los funcionarios públicos solo se preocuparon de cumplir con la formalidad específica, aprobando un estudio de impacto ambiental realizado solo con la versión de la misma empresa que realizaría las actividades económicas, como se refleja en la versión de la Procuraduría Pública del Ministerio de Energía y Minas al señalar que no ha violado precepto constitucional alguno.

Debe tenerse en cuenta que el proceso de consulta no debe reducirse a un procedimiento tipo audiencia ambiental, que se concreta en una sola reunión de consulta, desconociendo el carácter intercultural del procedimiento y del proceso y que este no puede ser absuelto en una sola reunión. Una consulta previa realizada íntegramente debe respetar los requerimientos de un diálogo intercultural y la reflexión interna de los pueblos indígenas sobre el tema, al mismo tiempo que garantizar eficiencia y eficacia gubernamental ${ }^{8}$. El Centro Internacional para los Derechos Humanos y el Desarrollo Democrático de la Organización Internacional de Trabajo dice que "solo podrá considerarse tal (consulta previa), el proceso que dé a los que son consultados la oportunidad de manifestar sus puntos de vista e influir en la toma de decisiones" ${ }^{\prime \prime}$. En este sentido reiteramos el dato que otorga el Tribunal Constitucional señalando que la empresa, así como entidades del Estado, han llevado a cabo una serie de talleres donde se transmitió a las comunidades nativas información sobre la empresa y los distintos procesos que se van a desarrollar en las zonas aledañas; pero no se realizó un proceso en el que se permitiera a las comunidades decidir y que su decisión sea respetada o mínimo tomada en cuenta.

La consulta debe realizarse teniendo en cuenta la representación y la autoridad de las comunidades, la interculturalidad y la lengua de las comunidades consultadas. Asimismo, debe realizarse con las instituciones tradicionales de cada pueblo y a través de sus autoridades o las organizaciones que las representen, que son las indicadas para manifestar los impactos sociales y culturales que un proyecto pueda generar. En la sentencia del Tribunal Constitucional no se señala que la información haya sido dirigida respetando la representación y autoridad de las comunidades, sino que se señala que se realizaron talleres en general.

Los funcionarios deben desarrollar el rol de facilitadores, orientadores y defensores de los derechos étnicos y territoriales y deben tener en cuenta que la consulta permite la relación directa comunidad-Estado, la cual debe fortalecerse sobre la base de la credibilidad y confianza mutua. Con su apoyo, las comunidades deben ser capacitadas previamente al desarrollo de la consulta 
sobre el significado, el alcance y el procedimiento para llevarse a cabo. Además deben constituirse en punto de apoyo e información oportuna para las partes $^{10}$. En este aspecto es importante resaltar que el funcionario público o autoridad prefiere apoyarse en normativa específica que señale sus funciones en estos casos, por tanto, es imperativa la tarea que el Tribunal Constitucional deja a cargo del legislador para que desarrolle los alcances, detalles, condiciones y vinculatoriedad del derecho de consulta establecido en el Convenio $\mathrm{N}^{\circ}$ 169 de la Organización Internacional de Trabajo.

Es deber del sector productivo o los dueños del proyecto facilitar el acceso a la información previa, objetiva, trasparente y oportuna y proporcionar los mecanismos para el uso eficiente de la misma, dado que, en su mayoría, las comunidades no saben qué hacer ni cómo interpretar información muy especializada. Por eso, deberán propiciar los espacios para la socialización del proyecto y deben facilitar a las comunidades asesores (elegidos por ellas) que traduzcan y expliquen en un lenguaje sencillo y claro, los códigos de información técnica, socioeconómica y cultural que contienen los estudios de impacto ambiental $^{11}$.

Finalmente, respecto al acuerdo se debe tener en cuenta que se deben establecer documentos escritos y claros de las condiciones para la realización de la obra, así como de las medidas de mitigación de la actividad para garantizar la identidad cultural y derecho a gozar de un medio ambiente sano de la comunidad. Deben establecerse mecanismos para que una vez culminado el proceso se socialicen los acuerdos con toda la comunidad, así como planes de seguimiento y control de las medidas. En esa medida, la judicatura nacional protegerá de mejor manera los derechos de los pueblos originarios.

\section{CONCLUSIONES}

La sentencia comentada es criticable en el sentido de que basa su decisión en temas formales, esto es el plan maestro, como requisito que exigen las normas específicas; y no establece su fallo en función de los temas que considera importantes pero tangenciales al caso concreto. El Tribunal Constitucional ha perdido la oportunidad de expedir un precedente vinculante que no solo reconozca sino que efectivice los derechos a la identidad étnica y cultural de las comunidades nativas, junto con el derecho a la consulta previa y a participar en la ejecución y evaluación de políticas que los afectan directamente.

En el caso concreto, la efectivización del derecho a la consulta fue olvidada en la decisión final, que solo condiciona la realización de la última fase de la eta- 
pa de exploración y la etapa de explotación dentro del área protegida (Área de Conservación Regional denominada Cordillera Escalera) a la realización del plan maestro.

En el contexto nacional, el reciente conflicto social en la Amazonía tiene especial relevancia para los temas que comentamos. El origen de este conflicto fue la dación de los Decretos Legislativos № 1015 y 1073 que modificaron el tema de la transmisión de propiedad dentro de las comunidades nativas; los representantes de estas comunidades solicitan la derogación de estas normas por considerarlas lesivas a los intereses selváticos (ya que no hubo proceso de consulta previa como establece el Convenio $N^{\circ} 169$ de la Organización Internacional de Trabajo) y exigen además un modelo alternativo de desarrollo para la selva. El Tribunal Constitucional ahora sí deberá decidir sobre este tema, dado que la Defensoría del Pueblo interpuso una demanda de inconstitucionalidad contra estas dos normas, por considerar que, además de violar el Convenio $N^{\circ} 169$, el Gobierno se habría excedido en sus facultades legislativas.

La futura decisión del Tribunal Constitucional debería contemplar un reconocimiento y una estructura fundamental de aplicación y contenido del derecho a la consulta previa, en el marco de la normativa internacional, interpretando la normativa nacional en base a principios y jurisprudencia comparada.

1 Orellana, Marcos A. «Fragmentación y acumulación de regímenes internacionales: los derechos indígenas vs. privilegios de los inversionistas». En: Aylwin Oyarzún, José y Aylwin, José (Comps.). Derechos humanos y pueblos indígenas. Selección de las ponencias presentadas al seminario: “Derechos humanos y pueblos indígenas; tendencias internacionales y realidad local", organizado por el Programa de Derechos Indígenas del Instituto de Estudios Indígenas de la Universidad de la Frontera en Temuco. Chile. Julio de 2003, 2004, pp. 44-54, p. 51.

2 Londoño Toro, Beatriz citada por Amparo Rodríguez, Gloria. «La consulta previa a pueblos indígenas». En: Parra Dussán, Carlos; Amparo Rodríguez, Gloria. Comunidades étnicas en Colombia, (Universidad del Rosario -Facultad de Jurisprudencia). 2005, p. 115.

3 Aroca Medina, Javier. «Derechos de los pueblos indígenas en el caso peruano». En: Aylwin Oyarzún, José y Aylwin, José (Comps.). Ob. Cit., p. 91.

4 Así lo reseña Bazán, Víctor. «Los derechos de los pueblos indígenas en Argentina: Diversos aspectos de la problemática. Sus proyecciones en los ámbito interno e internacional». Boletín mexicano de derecho comparado. Nueva serie. Año XXXVI. No 108. Septiembre - diciembre 2003, pp. 759-838.

5 Sentencia SU-039 de 1997 M.P. Antonio Barrera Carbonell.

6 Amparo Rodríguez, Gloria. Ob. Cit., p. 118.

Aroca Medina, Javier. Ob. Cit. p. 92.

8 En este sentido lo resalta Amparo Rodríguez, Gloria. Ob. Cit., p. 126.

9 Londoño Toro, Beatriz, citada por: Amparo Rodríguez, Gloria. Ob. Cit., p. 127.

10 Así lo señala correctamente Amparo Rodríguez, Gloria. Ob. Cit., p. 132.

11 Ibídem, p. 134. 